\title{
Rojas, I. (2018). Blas Valera: Primer cronista, poeta y lingüista peruano. Lima: Polisemia.
}

Este es un libro que dilucida, así lo creemos, la anonimia de autor de una obra importante sobre el quechua, impresa en Lima en 1586 por Antonio Ricardo. Dicho libro se titula Arte y vocabulario en la lengua general del Perú llamada Quichua, y en la Española. Lo que el libro de Ibico Rojas nos dice es que el autor de ese Arte y Vocabulario es el chachapoyano Blas Valera, mencionado siempre por Garcilaso por sus aportes de datos históricos. Valera era sacerdote jesuita y activo participante en el III Concilio Limense. En el impreso de Antonio Ricardo no figura nombre del autor pero si del impresor, y éste deja bien claro que no era autor del libro en referencia.

El libro publicado por Ibico Rojas tiene tres partes. La primera con el nombre de Tragedia y salvación, trata de la conquista española del Perú y de la realidad que surge de ese acto para los peruanos originarios. La segunda parte tiene como tema central la presencia en el Perú de la Congregación de los Jesuitas y su actuación en la evangelización y relaciones sociales de segregación y discriminación. La tercera parte trata de Blas Valera, de su formación como humanista de su época $y$ del fin de la anonimia de autor de la obra Arte y Vocabulario por reconocerse a Valera como su autor, que hace de él el primer lingüista peruano por su condición de haber nacido en Chachapoyas (3 de febrero de 1545), de madre indígena, Francisca Pérez, y de padre español, el encomendero Luis Valera.

Valera podría haber tenido un nombre nativo, propio de la cultura de su madre, que pudo ser en quechua o quizá en chacha. Él hablaba quechua y aimara, seguramente también jacaru (de Huarochirí); también latín y castellano con corrección. Esto llama la atención, pues lo que tenía como datos para aprender castellano -con corrección-, debieron ser pocos comparados con los que tenía para aprender quechua o chacha; de esta última lengua no se sabe nada a través de él, probablemente porque la asimilación al quechua de los chacha fue muy intensa y su lengua muy debilitada y marginada. En todo caso, su obra perdida Historia occidentalis pudo habernos dado información pertinente.

Es bastante probable que Valera también conociera griego y hebreo (no necesariamente que hablara), además de las lenguas indígenas chimú /quingnam y culle, de la costa y sierra centro norteñas del Perú. Se podría decir que tenía don 
de lenguas, algo muy apreciado en la época por los misioneros. Fue reconocido como un excelente "predicador de indios», es decir en lenguas indígenas peruanas.

Blas Valera era una persona culta de su época. En el campo lingüístico, como dice Rojas, elaboró "conceptuaciones lingüísticas sobre las entidades y estructuras de la lengua quechua, que relucían por contraste con las de la lengua castellana». Su experiencia de saber quechua y latín debe haber sido la ecología que le permitió hacer contrastes y comparaciones entre tales lenguas. Incidentalmente, al final de la parte que se refiere a Vocabulario en su libro Arte y Vocabulario ..., Valera inserta cuatro páginas con el título Annotaciones, estas revelan una alta comprensión del sistema de parentesco quechua, como si fuera un especialista en la materia especifica.

Ibico Rojas señala como una de las obras importantes de Valera: «La Historia occidentalis», que era su gran relato sobre el antiguo Perú hasta los primeros años de la Colonia Esta obra no fue impresa por haber sido destrozada "por manos extrañas». Por lo que se puede apreciar ahora sobre Valera «la mano extraña» habría destrozado una obra escrita no por un simple "doctrinero», sino por alguien con ideas originales para su tiempo. La sospecha es que Valera era objeto de discriminación e incomodidad por su condición de mestizo meritorio, maltratado no por «intervenir a una mujer» en Potosí, sino por reivindicar la cultura y la lengua del incario.

La venida de jesuitas al Perú fue auspiciada por el Virrey Toledo. La orden jesuítica tenia renombre por eficiente en el trabajo misional. En Lima edificaron la iglesia de San Pedro y se encargaron de conducir el Colegio de San Pablo y el Colegio Real para acercarse a los indígenas y conocerlos.

La formación de los misioneros Jesuitas preveía estancias de aprendizaje en América, una en Popayán (Colombia) como introducción para el trabajo misional en nuevos pueblos, geografías y culturas; luego, otra en Quito para asegurar eficiencia en el manejo del quechua, sea para internarse en la Selva o en los Andes. Como es obvio, estas provisiones tenían un buen resultado en el desempeño misional ente los pueblos indígenas americanos. Con relación a lingüistas es interesante la estandarización del quechua para el servicio misional que llevaron a cabo los religiosos en el Perú, especialmente los jesuitas, que se aplica luego a otros idiomas, cuyas semejanzas culturales fueron una buena base para que funcionara la estandarización a partir del quechua. Este trabajo genera prestigio para el quechua, motivando su aprendizaje casi generalizado. En esta perspectiva es de notar que Rojas señala como lenguas generales en el Perú andino costeño

\section{$178 \quad$ Lengua \& Sociedad}


en tiempos de Valera al quechua, aimara, puquina, chimú (quignam) y culle. De otro lado, Rojas anota que «Valera consideraba entre otros tantos temas el multilingüismo andino, el prestigio de la lengua cortesana en el Tawantinsuyo y los lineamientos de política lingüística más apropiada para la cristianización»

Creemos que la referencia de Primer cronista, poeta y lingüista peruano son adecuados con relación a Blas Valera. Para lo de cronista la comparación es con Garcilaso; para lo de lingüista no hay con quien comparar, es el primero.

Hay algunas preguntas que debemos plantearnos para avanzar en el conocimiento de Valera. Me permito señalar las siguientes: ¿Hay algo de la lengua chacha en Blas Valera, en su obra Arte y vocabulario...? ¿Qué quechua aprendían los chachapoyanos en tiempos de Valera: ¿la variedad local o la variedad cusqueña? ¿Qué cultura verbalizaba el quechua que aprendió Valera en Chachapoyas: cultura chacha o cultura mestiza chacha-quechua? ¿Aprendió Valera solo quechua y castellano mientras vivió en Chachapoyas, o también sabía la lengua chacha, que era la lengua originaria de la zona? ¿Hay algo de esta lengua en el quechua o en el castellano de B. Valera?

Gustavo Solís Fonseca 